\title{
Review on Properties of Bio plastics for Packaging Applications and its Advantages
}

\author{
Byreddy Naveena* and Ankita Sharma
}

Department of Post Harvest Process \& Food Engineering, Jawaharlal Nehru Krishi Vishwa Vidyalaya, Jabalpur, Madhya Pradesh, India

*Corresponding author

\section{A B S T R A C T}

Keywords

Biodegradation, Ecological problems, Flora and Fauna, Biopolymers

\section{Article Info}

Accepted:

10 April 2020

Available Online:

10 May 2020
Plastics are widely used for manufacturing of packaging materials because of their performance and ease in production. With the advent of food processing industries there is a great demand for petroleum based packaging materials for food applications. However, because of their resistance to biodegradation, increased use of plastics has created serious ecological problems to the environment. Moreover burning these plastic materials produce toxic gases which are very much injurious to both flora and fauna. Food industry is a major consumer of plastic as a packing material for the food items. As Biopolymers easily degrade in the environment, they can be used as a solution to the problems posed by plastics and also mimic the properties of conventional polymers. Instead of using these typical plastic materials biodegradable materials can be more effectively used to protect the food items and also prevent the degradation of our environment.

\section{Introduction}

The term packaging is referred to product protection, security and improving usability allows with provision for safe handling and use. Han, H. $\mathbf{J}^{7}$ stated that apart from preservation, packaging also has secondary functions such as selling and sales promotion, which contributes significantly to a business profit. Commonly used packaging materials are paper, wood, glass, metals, plastic and composites. According to Siracusa et $a l^{14}$.,because of the good mechanical performance such as tear and tensile strength, good barrier to carbon dioxide, oxygen, anhydride and aroma compound, and heat sealability and because their huge availability at relatively low cost, petrochemical-based plastics such as polyvinylchloride (PVC), polypropylene (PP), polyethylene (PE), 
polyamide (PA), polyethylene terephthalate (PET) and polystyrene (PS) have been progressively used as packaging materials. Jayasekar et $a l^{10}$., examined that increased use of petroleum based plastics has both environmental and health hazards. It also affects the health of workers who are related with cleaning or maintaining the processing equipments which led to serious ecological problems due to their total nonbiodegradability.

As plastic shows superior properties like of non- permeability, inert to environment, durability, lightness, stability and availability, they are widely used for packaging. Ashok et $a l^{3}$., stated that these properties of plastic also make them last in the environment forever and accumulate as solid waste, if not recycled properly. Today, polymers are an integral part of contemporary life because of their desirable properties including stability, resilience and ease in production. Ana RVF et $a l^{2}$., stated that the environmental impact caused by excessive quantity of nondegradable waste materials is necessitating research and efforts to develop new alternate materials that can be manufactured with the utilization of environmentally friendly raw materialsi.e., "bio-plastics".

Song et $a l^{15}$,stated that Polymers that are capable of undergoing decomposition into $\mathrm{CO}_{2}, \mathrm{CH}_{4}, \mathrm{H}_{2} \mathrm{O}$, and inorganic compounds under suitable conditions of temperature, moisture, and oxygen or biomass through predominantly the enzymatic action of microorganisms are known as Biodegradable polymers. Sorrentino et $a l^{16}$., stated that the biodegradable packaging materials are those that undergo the process of degradation by naturally occurring organisms, such as bacteria, yeast, or fungi and Siracusa et $a l^{14}$., examined that these can be used as fertilizer or humus when composted.
Although bio plastics are considered to develop eco- friendly food packaging materials, they also have some limitations such as poor mechanical and barrier properties and high production cost. According to Jain and Tiwari ${ }^{9}$ by blending two or more biopolymers, their mechanical and barrier properties can be improved and high production cost drawback can be managed by utilizing the low cost of renewable resources such as agricultural wastes.

Doppalapudi et $a l^{4}$., stated that according to researches, based on the origin and production, biopolymer based packaging materials can be divided into three main groups:

\section{Group 1}

This constitutes polymers which are directly extracted or removed from biomass. Certain polysaccharides such as starch, cellulose, and proteins (like casein and gluten) constitute represent this category. All these are, by nature, hydrophilic and somewhat crystalline and create problems while processing. Further, their performances are also poor especially in relation to packaging of moist food products. Malathy et $a l^{l 1}$., stated that, these polymers have excellent gas barrier properties which make them suitable for their utilization in food packaging industry.

\section{Group 2}

This includes polymeric materials which are synthesized by a classical polymerization procedure such as aliphatic aromatic copolymers, aliphatic polyesters, poly-lactide, aliphatic copolymer (CPLA), using renewable bio- based monomers such as poly (lactic acid) and oil-based monomers like polycaprolactones. Polylactic acid (PLA), a biopolyester polymerized from lactic acid 
monomers are good examples of polymers produced by classical chemical synthesis using renewable bio-based monomers. PLA may be plasticized with its monomers or, alternatively, oligomeric lactic acid. PLA can be formed into blown film, injected mould objects and coating.

\section{Group 3}

Polymers which are produced by microorganisms or genetically modified bacteria constitute this group. According to Mangaraj et $a l^{12}$., till date, this group of biobased polymers consists mainly of the polyhydroxy-alkanoates but developments with bacterial cellulose and other polysaccharides are also in progress.

\section{Preferable properties of bio plastics for packaging application}

\section{Gas barrier properties}

In food packaging industry, to withstand shelf life and to retain quality of food during the process of storage, specific gas pressure conditions are required. Weber C.J ${ }^{17}$ stated that, the gas mixture consists of oxygen, nitrogen, carbon dioxide or combination of these gases in most packaging applications. To withstand certain gas compositions inside the package, materials need gas barrier properties. Gas barrier properties of bio plastics are closely related to their permeation capacity i.e., capacity of material to exchange low molecular weight substances through film. The use of multi layers gives better barrier properties for food packaging materials. For producing multi layers various techniques used such as, atomic deposition technique, electron beam evaporation, magnetron sputtering and sol/gel method. Weber reported that gas barrier properties of PLA and PLA based materials are closely depend with humidity. Guinault et $a l^{6}$., studied the influence of crystallinity on mechanical properties and gas barrier properties of PLA films for food packaging.

\section{Mechanical and thermal properties}

Satheesh Kumar et $a l^{13}$,, stated that good mechanical and thermal properties ensure the protection of product against thermal and/or mechanical damage during period of storage. Thermal and mechanical properties are critical in which they determine suitability of bio plastic for certain applications. Polymers with high gas barrier properties are required for food packaging industry where as competitive mechanical properties are required for automobile industry. Various techniques are applied in the processing of bio plastics like plasticization, blending with polymer, and converting bio plastic to thermoplastic for improving properties. Iguchi et $a l^{8}$., stated that Plasticization process can alter mechanical and thermal properties of bio plastics, by increasing thermal degradation temperature of bio plastic.

\section{Moisture barrier property}

According to Alavi et $a l^{l}$.,moisture barrier property of bio plastic refers to the ability of a bio plastic to resist the entry of undesired vapour are characterised by permeability, diffusivity, solubility across the barrier and also the affinity of the packaging materials towards moisture, which is evaluated by water vapour transmission rate. Weber ${ }^{17}$ studied that hydrophobic character of Bio or bio-based materials reduces moisture barrier property of natural polymer. Barrier properties depend upon morphological properties of the material such as crystallinity and chain conformation. Alavi et $a l^{l}$., examined that as crystallinity of material increases barrier properties of material also increases. The shelf life of food in food packaging industry increases with increasing moisture barrier. 


\section{Biodegradability}

Ghalem and Mohamed $^{5}$ stated that Biodegradability of a polymer means that a material is capable of being broken down into smaller compounds by the action of naturally occurring microorganisms like bacteria, fungi or algae in the environment where biodegradation is occurring. The process of biodegradation is influenced by the environmental conditions (e.g. temperature, moisture, available nutrients and $\mathrm{pH}$ ). Bio degradation as process can be explained in two steps. First step characterized as degradation or de fragmentation, which is initiated by heat, moisture, microbial enzymes. Second step is bio degradation, which transforms longer molecular substance into smaller compounds, initiated by naturally occurring enzymes, and acids.

\section{Advantages of Biodegradable packaging film}

These packaging materials are biodegradable and compostable, no toxic residues are produced.

Biopolymers are obtained from renewable resources mainly from agricultural resources and other feedstock.

One of the main advantages of biodegradable plastic is a significant reduction in carbon emissions during the manufacturing process.

They are light in weight.

These packaging materials are transparent due to which the food item packed in it can be easily identified.

They consumes less energy.

They have good gas barrier properties which improve the shelf life of the food item.

They do not react with the food items stored.

Antimicrobial agents can be integrated effectively with these polymers.

When blended with plasticizers the mechanical properties are improved.
They can easily be moulded into any desired or complex designs.

Films formed from various ingredients can be easily laminated together.

To preserve the aroma of food, they can be successfully used for microencapsulation.

These biodegradable materials are resistant to $\mathrm{UV}$ radiations.

It is concluded that competitive bio plastics can be derived from natural feedstock, microbial actions of microorganisms or chemical synthetic methods. During processing and storage, before adopting any bio based packaging for food there has to be proper studies on the interaction between food components and biopolymers. Suitability of packaging materials depends on the mechanical and thermal properties of bio plastic. Mechanical and barrier properties of bio plastics can be modified with plasticization effect, blending of polymers and reinforcement of nano-material altogether brings out suitable packaging materials for industrial use. Future researches have to be more focused on adding value to the packaging materials, i.e., use of smart sensors, nanotechnology, etc., which will not only maintain the integrity, but also communicate the information about the product to the consumers.

\section{References}

1. Alavi S., Thomas S., Sandeep K.P., et al., Polymers for packaging applications, Polym J. 2014, 127p.

2. Ana RVF, Vítor DA, Isabel MC (2016) Polysaccharide-based membranes in food packaging applications. Membranes 6(2):22.

3. Ashok A., Mathew M., Rejeesh C.R. Innovative value chain development of modified starch for a sustainable environment: a review, Int J Polym Sci 
Eng. 2016; 2(1): 20-32p.

4. Doppalapudi S, Jain A, Khan W, Domb AJ (2014) Biodegradable polymers-an overview. Polym Adv Technol 25:427435.

5. Ghalem B.R., Mohamed B. Antibacterial activity of leaf essential oils of Eucalyptus globulus and Eucalyptus camaldulensis, Afric J Pharm Pharmacol. 2008; 2(10): 211-5p.

6. Guinault A., Sollogoub C., Domenek S., et al., Influence of crystallinity on gas barrier and mechanical properties of pla food packaging films, Int J Mater Form. 2010; 3: 603p. doi: 10.1007/s12289010-0842-9.

7. Han, H. J. (2005). New technologies in food packaging. In: Han $\mathrm{H} J$ (Ed). Innova- tions in Food Packaging. Elsevier, Academic Press. 1, 3-11.

8. Iguchi M., Yamanaka S., Budhioni A. Bacterial cellulose - a masterpiece of nature's arts, J Mater Sci. 2010; 35: 1$10 \mathrm{p}$.

9. Jain, R., and Tiwari, A. (2015). Biosynthesis of planet friendly bio plastics using renewable carbon source. J. Environ. Heal. Sci. Eng. 13, 11.

10. Jayasekara R, Harding I, Bowater I and Lonergan G (2005). Biodegradability of a selected range of polymers and polymer blends and standard methods for assessment of biodegradation. Journal of Polymer and Environment, 13(3): 231-251.

11. Malathy AN, Santhosh KS, Nidoni U (2014). Recent trends of biodegradable polymer: biodegradable films for food packaging and application of nanotechnology in biodegradable food packaging. Curr Trends Technol Sci 3:73-79.

12. Mangaraj S, Goswami TK, Panda DK (2015) Modeling of gas transmission properties of polymeric films used for MA Packaging of fruits. J Food Sci Technol 52(9):5456-5469.

13. Satheesh Kumar M.N., Yaakob Z., Siddaramaiah, Biobased materials in food packaging applications, In: Handbook of Bioplastics and Biocomposites Engineering Applications. Srikanth Pilla (Ed.), 12159 p.

14. Siracusa, V., Rocculi, P., Romani, S., and Dalla Rosa, M. (2008). Biodegradable polymers for food packaging: A review. Trends in Food Science and Technology, 19(12), 634-643.

15. Song, J. H., Murphy, R. J., Narayan, R. and Davies, G. B. H. (2009). Biodegradable and compostable alternatives to conventional plastics. Philosophical transactions of the Royal Society of London B-Biological Science 364, 2127-2139.

16. Sorrentino, A., Gorrasi, G. and Vittoria, V. (2007). Potential perspectives of bionanocomposites for food packaging applications. Trends in Food Science and Technology 18, 84-95.

17. Weber C.J. Bio based packaging materials for the food industry, R Vet Agric Univ. $2000,4 p$.

\section{How to cite this article:}

Byreddy Naveena and Ankita Sharma. 2020. Review on Properties of Bio plastics for Packaging Applications and its Advantages. Int.J.Curr.Microbiol.App.Sci. 9(05): 1428-1432. doi: https://doi.org/10.20546/ijcmas.2020.905.163 